\title{
Tendering Process: Improvement of Analysis and Evaluation of Tenders based on the Use of Fuzzy Logic and Rule of Proportion
}

\author{
Amadou Diabagate \\ Laboratory of Computer \\ Sciences, Systems and \\ Telecommunication \\ Faculty of Sciences and \\ Technology \\ Tangier, Morocco
}

\author{
Abdellah Azmani \\ Laboratory of Computer \\ Sciences, Systems and \\ Telecommunication \\ Faculty of Sciences and \\ Technology \\ Tangier, Morocco
}

\author{
Mohamed El Harzli \\ Laboratory of Computer \\ Sciences, Systems and \\ Telecommunication \\ Faculty of Sciences and \\ Technology \\ Tangier, Morocco
}

\begin{abstract}
This paper proposes improvements concerning the analysis and the evaluation of tenders in the tendering process. At first, a new method of analysis and evaluation of tenders using the rule of proportion is proposed. Secondly, the principles of fuzzy logic are introduced in order to reconsider limits from the classical logic in the analysis and evaluation of tenders.
\end{abstract}

This work is a step towards the modeling of an IT solution integrating the concepts of artificial intelligence and decision support in the context of e-government (e-tendering).

\section{General Terms}

Making decision, Artificial intelligent, Public procurement, Tendering, Analysis and evaluation of tenders.

\section{Keywords}

Tendering, Artificial intelligence, Decision support, Fuzzy logic, Rule of proportion, Public procurement, Method of analysis and evaluation of tenders, Company, State, etendering, e-government, dematerialization, IT solutions.

\section{INTRODUCTION}

The award of public procurement constitutes a major economic issue for the state and for the companies [1][2].Public procurements are granted through different modes including tendering [3].

Many shortcomings exist in the tendering process [4] generating a confidence crisis between the different actors and an unfavorable environment for economic growth.

The dematerialization of tendering process via efficient and powerful IT solutions integrating the techniques of artificial intelligence and decision support is undoubtedly one of the most effective ways to correct these shortcomings[5][6].

This article which is part of the tendering process dynamics improvement is particularly focused on the analysis and evaluation of tenders. It is to use the concepts of artificial intelligence and decision support to fully solve or, at least partially, the shortcomings of this step which is at the heart of the tendering process.

This is an upstream work for the proposal of an IT solution integrating the concepts of artificial intelligence and decision support which dematerializes and improves the entire process of tendering.

\section{TENDERING PROCESS}

The tendering, due to its specificities, is generally preferred to other modes of public procurement [7][8].Legislation in some countries imposes the tendering when the amount of the contract becomes large. There are two types of tendering: the open tendering (every enterprise can submit a tender) and restricted tendering (only enterprises that have been authorized after preselecting can submit tenders)[3].The schema in figure 1 shows the main steps of the tendering process [9].

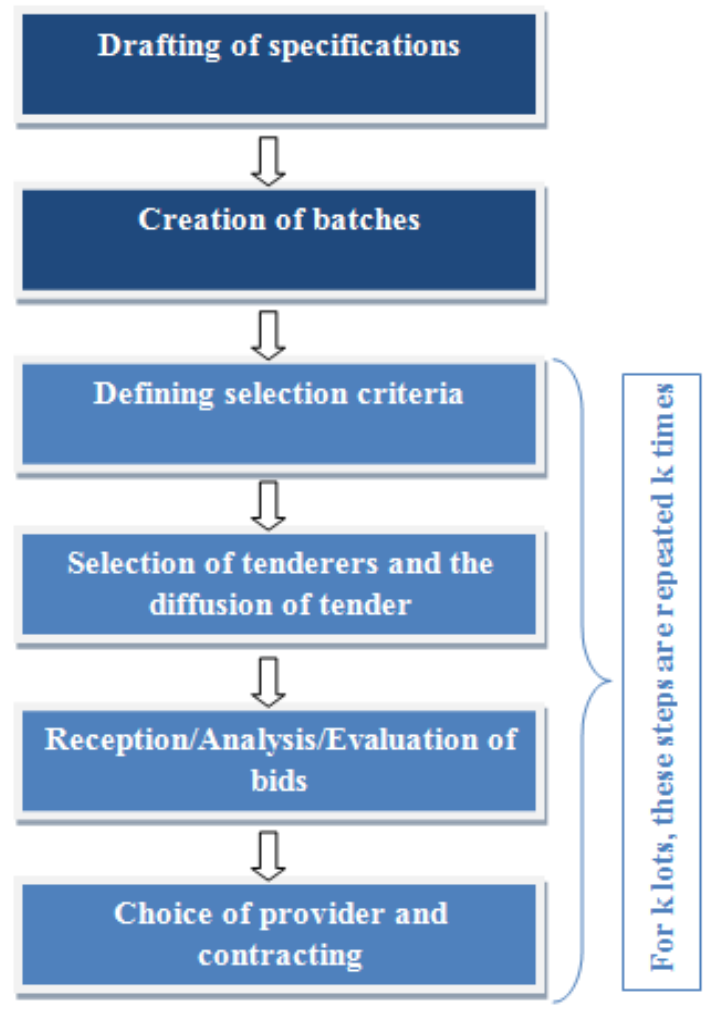

Fig 1. Steps of tendering process

\subsection{The award criteria of tenders}

The analysis and evaluation of tenders is a decisive step in the tendering process [10][11]. Indeed, tenders badly analyzed and badly evaluated compromise the choice of the best tender and this has harmful consequences on the service quality but 
worse, it creates a confidence crisis between companies and the contracting authorities.

The principle established to analyze and evaluate tenders is based on the use of criteria called criteria for awarding contracts [12]. They must be designed so as to be nondiscriminatory and linked to the object of the contract. The award criteria generally used for the analysis and evaluation of tenders are:

- The quality,

- The price,

- The technical value,

- The Aesthetic and functional,

- The performance in terms of environmental protection,

- The performance in terms of employability of people in difficulty,

- The global cost of use,

- The profitability,

- The team expertise,

- The innovative character,

- The after-sales service and technical assistance,

- The date of delivery,

- The delivery time or performance,

- The references

\subsection{The methods of analysis and evaluation of tenders}

There are two main methods of analysis and evaluation of tenders: methods based on the weighting of the criteria and those based on the prioritization of the criteria [13]

\subsubsection{The methods based on the weighting of criteria}

Consider the following notations:

$$
\left\{\begin{array}{l}
\left\{\mathrm{O}_{\mathrm{i}}\right\}_{\mathrm{i}=1, \ldots, \mathrm{n}} \text { set of tenders } \\
\left\{\mathrm{X}_{\mathrm{j}}\right\}_{\mathrm{j}=1, \ldots, \mathrm{p}} \text { set of criteria }
\end{array}\right.
$$

$\left(\mathrm{R}\left(\mathrm{O}_{\mathrm{i}}\right)\right.$ : result of tender $\mathrm{O}_{\mathrm{i}}$ $\left\{\mathrm{N}_{\mathrm{ij}}\right.$ : note of tender $\mathrm{O}_{\mathrm{i}}$ according to the criterion $\mathrm{X}_{\mathrm{j}}$

There are several methods based on the weighting of the criteria and two of them are extensively used.

\subsubsection{First method}

This method is the simplest. It is to give a note for each tender according to each criterion. Then, for each tender, a weighted sum of these notes obtained according to all criteria is made. This sum represents the total result obtained by the tender. The same is done for the other tenders and total results obtained are compared. The best tender is the one that will have the highest total result [14].The total result for the tender $O_{i}$ is given by (1):

$$
R\left(O_{i}\right)=\sum_{j=1}^{p} n_{j} N_{i j}
$$

The best tender $\left(O_{m}\right)$ according to the criterion $X_{j}$ is the tender such that

$$
N_{m j}>N_{i j} \forall i \neq m
$$

The best tender $\left(O_{M}\right)$ of the tendering is such that:

$$
R\left(O_{M}\right)=\sum_{j=1}^{p} n_{j} N_{M j}>R\left(O_{i}\right)=\sum_{j=1}^{p} n_{j} N_{i j} \forall i \neq M
$$

\subsubsection{Second method}

This method makes a comparison of the tenders according to each criterion and gives the best tender $100 \%$ of points and makes a rule of proportion to give points to other tenders. It guarantees the principles of proportionality and equality in the treatment of tenders [14].

Let $O_{m}^{j}$ be the best tender after comparing the tenders according to the criterion $X_{j}\left(N_{m j}=N_{\max }^{j}\right.$ The maximum note).

$$
\begin{aligned}
O_{m}^{j} & \Leftrightarrow N_{m j}=N_{\text {max }}^{j} \\
O_{i}^{j} & \Leftrightarrow \frac{o_{i}^{j}}{o_{m}^{j}} * N_{m j} \forall i \neq m
\end{aligned}
$$

$\frac{O_{i}^{j}}{O_{m}^{j}}$ is the ratio of comparison between $O_{m}^{j}$ and $O_{i}^{j}$

$R\left(O_{i}\right)=\sum_{j=1}^{p} \frac{O_{i}^{j}}{O_{m}^{j}} * N_{m j} \Rightarrow\left\{\begin{array}{l}\text { This is the result of } \\ \text { the tender } O_{\mathrm{i}} \text { if this } \\ \text { method is used for } \\ \text { all criteria }\end{array}\right.$

NB: Method can be changed to a criterion to another.

The best tender $\left(O_{M}\right)$ is such that:

$$
R\left(O_{M}\right)>R\left(O_{i}\right) \forall i \neq M
$$

The problem with this method is its relative aspect. Indeed, the tender to which $100 \%$ of the points are assigned is better than the others; this does not mean that it is intrinsically a good tender.

\subsubsection{The methods based on prioritization of criteria}

The prioritization of criteria is based on the establishment of hierarchical order among the criteria: it comes to draw up a list in which the criteria are generally in descending order of importance.

The use of methods based on the prioritization of criteria must be justified by demonstrating that it is inappropriate to use the weighting method considering the specificities of contract. The Prioritization method is simpler than weighting method since it consists to do the following operations:

- A notation of tenders according to the first criteria in descending order of importance.

- A choice based on this criterion alone, unless it leads to judge that all the tenders are equivalent, in which case the same operation is done with the second criterion, till a criterion which is able to discriminate the tenders. 


\subsection{Critical analysis of methods of analysis and evaluation}

Weighting methods are preferred to methods of prioritization because they globally evaluate tenders according all the criteria in order to decide between them. Every company knows precisely the assessment made of its tender according to each criterion

Concerning weighting methods, some are disadvantaged by the non-intrinsic evaluation of tenders and the rest is disadvantaged by the non-relative evaluation of tenders to the others [14].

A Good weighting method is the method that will be able to evaluate offers intrinsically and relatively from the other offers.

\section{PROBLEMATIC}

Many problems exist in the analysis and evaluation of tenders [15]. The importance of this step in the process of tendering made it important to pay attention to these problems and work to their resolutions. As problems, include:

- The shortcomings of existing methods of analysis and evaluation

- The wrong choice of the method used to analyze and evaluate

- The part of subjectivity in the analysis and evaluation of tenders

- The members of the tendering commission sometimes don't have all the skills required for the analysis and evaluation of tenders

- The lack of transparency in the analysis and evaluation of tenders due to exchange of bribes

- Inexistence or inefficiency of the control mechanism of the activities related to the analysis and evaluation of tenders

- The absence of a legal system for companies contesting the evaluation of tenders

\section{PROPOSAL OF SOLUTION}

\subsection{Proposal of a new method of analysis and evaluation of tenders}

The solution proposed aims to improve existing methods of analysis and evaluation of tenders. This improvement consists to combine the first method and relative method in order to analyze and evaluate tenders intrinsically and comparatively. Thus, a note (or points) is assigned to each tender according to each criterion. Then, summing the notes (or points) obtained by each tender and the result is assigned to the best tender.

Afterward, the rule of proportion is used to give the new notes (or the new points) of the other tenders. This new method has the merit to analyze and evaluate both the intrinsic value of the tender and its relative value to the other tenders.

Let $O_{m}^{j}$ be the best tender after comparing tenders according to the criterion $X_{j}\left(N_{m j}>N_{i j} \forall i \neq m\right)$.

The sum of the notes obtained by the tenders relative to the criterion $X_{j}$ is:

$$
\sum_{\mathrm{i}=1}^{\mathrm{n}} N_{i j}=S_{j}\left(N_{i j}\right)
$$

The rule of proportion is used to have the other tenders notes (points):

$$
\begin{aligned}
O_{m}^{j} & \Leftrightarrow S_{j}\left(N_{i j}\right) \\
O_{i}^{j} & \Leftrightarrow \frac{N_{i j}}{N_{m j}} * S_{j}\left(N_{i j}\right) \forall i \neq m
\end{aligned}
$$

If this method is used for all criteria then the result obtained by tender $O_{i}$ is:

$$
R\left(O_{i}\right)=\sum_{j=1}^{p} \frac{N_{i j}}{N_{m j}} * S_{j}\left(N_{i j}\right)
$$

\subsection{Integration of the principles of fuzzy logic in the analysis and evaluation of tenders}

The fuzzy logic will increase the degree of accuracy [16][17][18] of the notes $N_{i j}$ which will be used in the proposed method.This approach constitutes an improvement for the proposed method and for all other methods based on the use of notes $N_{i j}$.

Some award criteria such as team expertise, references ... are not easily quantifiable because the information they convey are often imprecise, uncertain. So it is important to increase the margin of precision in the analysis and evaluation of tenders by the using of fuzzy logic. To illustrate this point, the principles of fuzzy logic are introduced to analyze and evaluate tenders according to the criterion "reference". The same approach can be applied to other criteria. Given that the analysis and evaluation of tenders are made criterion by criterion, this approach based on fuzzy logic can be applied to some criteria to improve the entire step of analysis and evaluation of tenders [19][20].

The award criterion "reference" consists to ask bidder companies to indicate their achievements (previous contracts). This criterion serves to assess the experience and expertise of competing companies.

Two approaches are commonly used to assess references. The first consists to assign the same note to the references whatever their specificities. The second consists of taking account certain specificities such as seniority, the amount... The second approach which is undoubtedly better than the first can be improved by enlarging the field of specificities to be taken account and applying the principles of fuzzy logic.

\subsubsection{Parameterization}

\subsubsection{Linguistic input variables:}

Based on tendering documents and discussions with experts, five input variables have been retained which are presented in Table I.

TABLE I. Presentation of Linguistic Input Variables

\begin{tabular}{|c|c|}
\hline $\begin{array}{c}\text { Linguistic } \\
\text { variables }\end{array}$ & Meaning \\
\hline ConvNature & $\begin{array}{c}\text { The convergence degree of the nature of } \\
\text { the reference and the nature of the } \\
\text { contract subject to tender. (The universe } \\
\text { of discourse varying between } 0 \text { to 10) }\end{array}$ \\
\hline
\end{tabular}




\begin{tabular}{|c|c|}
\hline CompAmount & $\begin{array}{c}\text { The comparison of the amount of the } \\
\text { reference and the amount of the contract } \\
\text { subject to tender. (The universe of } \\
\text { discourse varying between 0 to 10) }\end{array}$ \\
\hline Seniority & $\begin{array}{c}\text { The appreciation of recent character of } \\
\text { the reference. (The universe of discourse } \\
\text { varying between 0 to 10) }\end{array}$ \\
\hline ConvLevInt & $\begin{array}{c}\text { The convergence between level(s) of } \\
\text { company intervention and the nature of } \\
\text { the contract subject to tender. (The } \\
\text { universe of discourse varying between 0 } \\
\text { to 10) }\end{array}$ \\
\hline RoleEnt & $\begin{array}{c}\text { The reach (importance) of the } \\
\text { intervention levels of the company in } \\
\text { achieving the reference. (The universe of } \\
\text { discourse varying Between 0 to 5) }\end{array}$ \\
\hline
\end{tabular}

The members of the committee for analysis and evaluation must establish the correspondence between the universes of discourse and the specificities of references according to each input variable. Clearly, they will assign new values to references taking into account the specificities of the reference, the specificities of the contract submitted to tendering and the universes of discourse.

Let us take the case of a tendering for the construction of a $100 \mathrm{~km}$ highway of which cost is estimated at 480 million euros (658 million dollars). Let us suppose a reference concerning the construction of a $250 \mathrm{~km}$ road. The table II shows how the members of the Committee will proceed to assign new values (These new values are those used in the fuzzy system).

\section{TABLE II. An Example of Correspondence}

\begin{tabular}{|c|c|c|c|}
\hline & $\begin{array}{c}\text { The } \\
\text { specificities of } \\
\text { the reference }\end{array}$ & $\begin{array}{c}\text { New } \\
\text { values }\end{array}$ & $\begin{array}{l}\text { Justification of new } \\
\text { values }\end{array}$ \\
\hline $\begin{array}{l}\text { Conv- } \\
\text { Nature }\end{array}$ & $\begin{array}{c}\text { construction of a } \\
250 \mathrm{~km} \text { road }\end{array}$ & $5,5 / 10$ & $\begin{array}{c}\text { The convergence } \\
\text { between the nature of } \\
\text { the reference and that } \\
\text { of the contract is } \\
\text { medium }\end{array}$ \\
\hline $\begin{array}{l}\text { Comp- } \\
\text { Amount }\end{array}$ & $\begin{array}{l}857 \text { million } \\
\text { dollars }\end{array}$ & $7 / 10$ & $\begin{array}{l}\text { The amount of the } \\
\text { reference is a little } \\
\text { higher than the } \\
\text { amount of the contract }\end{array}$ \\
\hline Seniority & 2years & $8 / 10$ & The reference is recent \\
\hline ConvLevInt & \begin{tabular}{|c|} 
levels of \\
intervention: \\
excavation, \\
upgrading, \\
Asphalt paving \\
\end{tabular} & $8 / 10$ & \begin{tabular}{|c|} 
The levels of \\
intervention of the \\
company and those of \\
the construction of the \\
highway converge \\
\end{tabular} \\
\hline RoleEnt & $\begin{array}{l}\text { levels of } \\
\text { intervention: } \\
\text { excavation, } \\
\text { upgrading, } \\
\text { Asphalt paving }\end{array}$ & $4 / 5$ & $\begin{array}{c}\text { The role of the } \\
\text { company was major in } \\
\text { the construction of the } \\
\text { road }\end{array}$ \\
\hline
\end{tabular}

\subsubsection{Linguistic output variables:}

According to discussions with experts, two output variables have been considered which are presented in table III.

\section{TABLE III. Presentation of Linguistic Output} Variables

\begin{tabular}{|c|c|}
\hline $\begin{array}{c}\text { Linguistic } \\
\text { variables }\end{array}$ & Meaning \\
\hline QualityRef & $\begin{array}{c}\text { The quality of reference. (The } \\
\text { universe of discourse varying } \\
\text { between 0 to 5) }\end{array}$ \\
\hline ContributionEnt & $\begin{array}{c}\text { The contribution of the company in } \\
\text { the realization of the reference. (The } \\
\text { universe of discourse varying } \\
\text { between 0 to 1) }\end{array}$ \\
\hline
\end{tabular}

- The output variable QualityRef varies as a function of input variables ConvNature, CompAmount and Seniority.

- The output variable ContributionEnt varies as a function of input variables RoleEnt and ConvLevInt. The quality of the reference can be very high but the company weakly contribute to its realization. ContributionEnt will allow taking into account the contribution of the enterprise.

\subsubsection{Definition of fuzzy sets, linguistic} terms and membership functions

The fuzzy sets have to be defined for each input variable and for each output variable. It allows to introduce the graduality by defining qualitative values (magnitudes) to consider, specifying when they are true or false. These values will become the linguistic terms of the rules base.

The membership function is to match to each input value its membership degree (between 0 and 1 value) to the fuzzy set [21]. In this study, the membership functions used have trapezoidal shapes as they are more appropriate for the input and output variables.

The figures $2,3,4,5,6,7,8$ represent the fuzzy sets, linguistic terms and membership functions of variables.

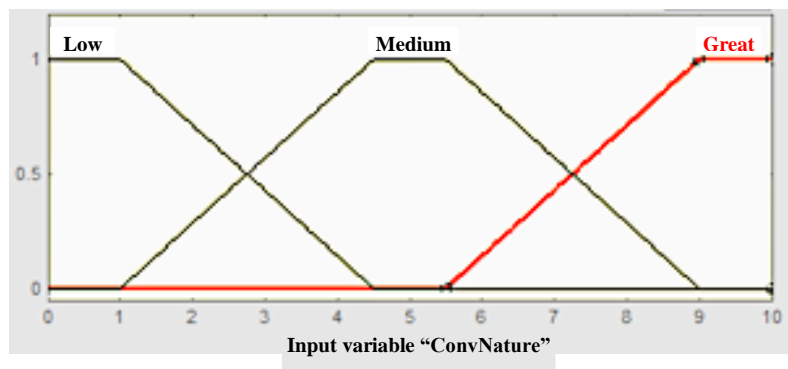

Fig 2. The membership function of the input variable «ConvNature» 


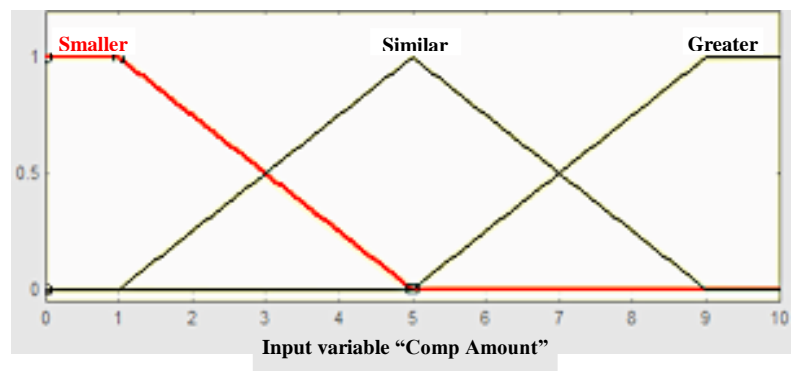

Fig 3. The membership function of the input variable «CompAmount»

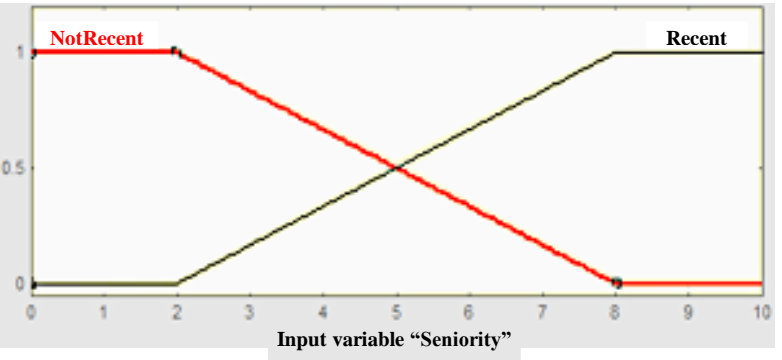

Fig 4. The membership function of the input variable «Seniority»

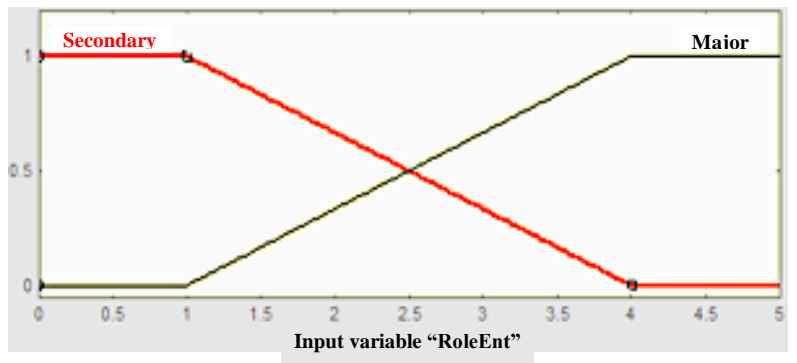

Fig 5. The membership function of the input variable «RoleEnt»

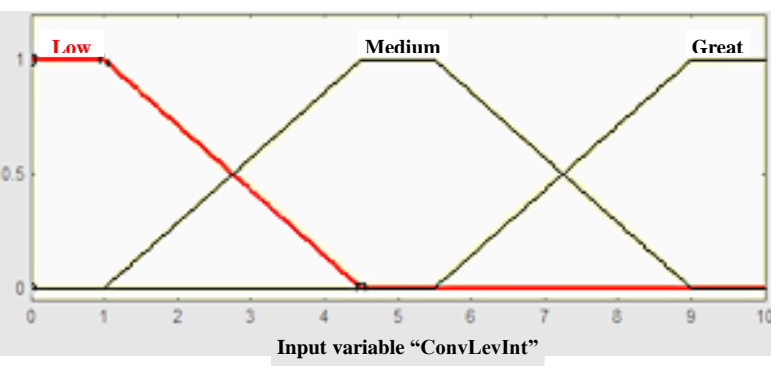

Fig 6. The membership function of the input variable «ConvLevInt».

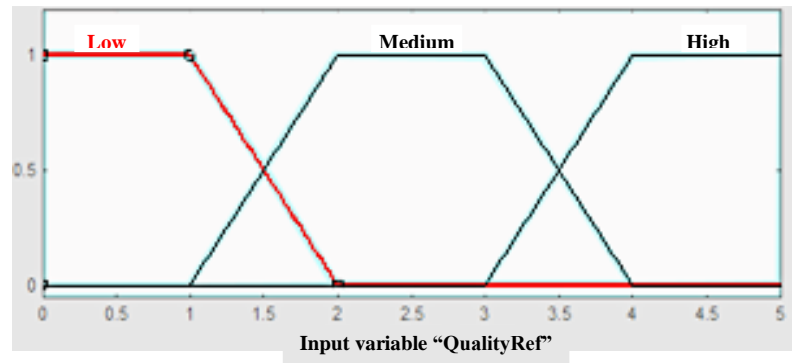

Fig 7. The membership function of the output variable «QualityRef»

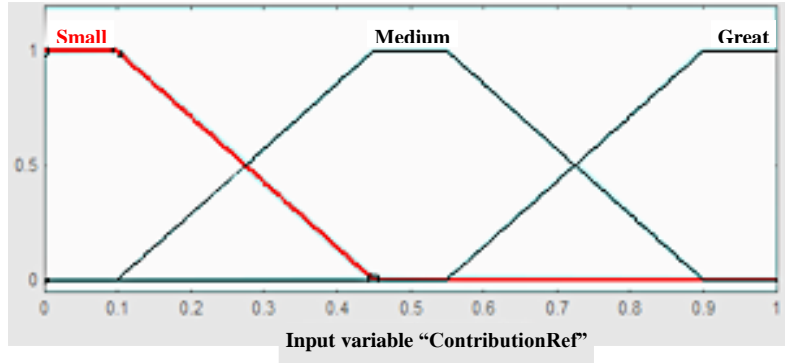

Fig 8. The membership function of the output variable «ContributionEnt»

5.2.2 The construction of the inference rules base The base of inference rules contains all the rules between the input variables of the fuzzy system and the output variables of that system. The rules are composed of a predicate and a conclusion. A predicate (the same for a conclusion) is a combination of proposals by operators [22-26].

The following rules base is proposed and it may be enriched by adding other inference rules.

TABLE IV. THE BASE OF INFERENCE RULES

\begin{tabular}{|c|c|}
\hline Rules & Composition of rules \\
\hline$R 1$ & $\begin{array}{c}\text { If «RoleEnt» is Major AND «ConvLevInt» is } \\
\text { Great THEN «ContributionEnt» is Great }\end{array}$ \\
\hline$R 2$ & $\begin{array}{l}\text { If «RoleEnt» is Major AND «ConvLevInt»is } \\
\text { Medium THEN «ContributionEnt» is Medium }\end{array}$ \\
\hline$R 3$ & $\begin{array}{c}\text { If «RoleEnt» is Major AND «ConvLevInt» is } \\
\text { Low THEN «ContributionEnt» is Small }\end{array}$ \\
\hline$R 4$ & $\begin{array}{c}\text { If «RoleEnt» is Secondary AND «ConvLevInt» } \\
\text { Great THEN «ContributionEnt» is Medium }\end{array}$ \\
\hline$R 5$ & $\begin{array}{c}\text { If «RoleEnt» is Secondary AND «ConvLevInt» } \\
\text { Medium THEN «ContributionEnt» is Small }\end{array}$ \\
\hline$R 6$ & $\begin{array}{l}\text { If «RoleEnt» is Secondary AND «ConvLevInt» } \\
\text { is Low THEN «ContributionEnt» is Small }\end{array}$ \\
\hline$R 7$ & $\begin{array}{c}\text { If «ConvNature» is Great AND } \\
\text { «CompAmount» is similar AND «Seniority» is } \\
\text { Recent THEN «QualityRef» is High }\end{array}$ \\
\hline$R 8$ & $\begin{array}{c}\text { If «ConvNature» is Great AND } \\
\text { «CompAmount» is similar AND «Seniority» is } \\
\text { NotRecent THEN «QualityRef» is Medium }\end{array}$ \\
\hline$R 9$ & $\begin{array}{c}\text { If «ConvNature» is Great AND } \\
\text { «CompAmount» is Greater AND «Seniority» is } \\
\text { Recent THEN «QualityRef» is High }\end{array}$ \\
\hline$R 10$ & $\begin{array}{c}\text { If «ConvNature» is Great AND } \\
\text { «CompAmount» is Greater AND «Seniority» is } \\
\text { NotRecent THEN «QualityRef» is Medium }\end{array}$ \\
\hline$R 11$ & $\begin{array}{c}\text { If «ConvNature» is Great AND } \\
\text { «CompAmount» is Smaller AND «Seniority» is } \\
\text { Recent } \text { THEN «QualityRef» is Medium }\end{array}$ \\
\hline$R 12$ & $\begin{array}{c}\text { If «ConvNature» is Great AND } \\
\text { «CompAmount» is Smaller AND «Seniority» is } \\
\text { NotRecent THEN «QualityRef» is Low }\end{array}$ \\
\hline$R 13$ & $\begin{array}{c}\text { If «ConvNature» is Great AND } \\
\text { «CompAmount» is Smaller AND «Seniority» is } \\
\text { NotRecent } \mathbf{T H E N} \text { «QualityRef» is Low }\end{array}$ \\
\hline
\end{tabular}




\begin{tabular}{|c|c|}
\hline$R 14$ & $\begin{array}{c}\text { If «ConvNature» is Medium AND } \\
\text { «CompAmount» is similar AND «Seniority» is } \\
\text { NotRecent THEN «QualityRef» is Low }\end{array}$ \\
\hline$R 15$ & $\begin{array}{l}\text { If «ConvNature» is Medium AND } \\
\text { «CompAmount» is Greater AND «Seniority» is } \\
\text { Recent } \text { THEN «QualityRef» is High }\end{array}$ \\
\hline$R 16$ & $\begin{array}{c}\text { If «ConvNature» is Medium AND } \\
\text { «CompAmount» is Greater AND «Seniority» is } \\
\text { NotRecent } \text { THEN «QualityRef» is Medium }\end{array}$ \\
\hline$R 17$ & $\begin{array}{c}\text { I } \mathrm{f} \text { «ConvNature» is Medium AND } \\
\text { «CompAmount» is Smaller AND «Seniority» } \\
\text { isRecent THEN «QualityRef» is Medium }\end{array}$ \\
\hline$R 18$ & $\begin{array}{l}\text { If «ConvNature» is Medium AND } \\
\text { «CompAmount» is Smaller AND «Seniority» is } \\
\text { NotRecent } \text { THEN «QualityRef» is Low }\end{array}$ \\
\hline$R 19$ & $\begin{array}{c}\text { If «ConvNature» is Low AND «CompAmount» } \\
\text { is Greater AND «Seniority» is Recent THEN } \\
\text { «QualityRef» is Medium }\end{array}$ \\
\hline$R 20$ & $\begin{array}{l}\text { If «ConvNature» is Faible AND } \\
\text { «CompAmount» is Greater AND «Seniority» is } \\
\text { NotRecent THEN «QualityRef» is Low }\end{array}$ \\
\hline$R 21$ & $\begin{array}{c}\text { If «ConvNature» is Low AND «CompAmount» } \\
\text { is similar THEN «QualityRef» is Low }\end{array}$ \\
\hline$R 22$ & $\begin{array}{c}\text { If «ConvNature» is Low AND «CompAmount» } \\
\text { is Smaller THEN «QualityRef» is Low }\end{array}$ \\
\hline
\end{tabular}

\subsubsection{The obtained results}

In view of adequacy of the results obtained with the method of Mamdani, this method was used with the following options:

- The method "AND" is represented by the Min function and the method "OR" by the Max function

- The implication «THEN» is represented by the function Min

- The aggregation is done by the Max function

- The defuzzification will be done by the method of centroid

The figures 9, 10,11, 12 and 13 represent the variations of the two output variables as a function of the input variables.

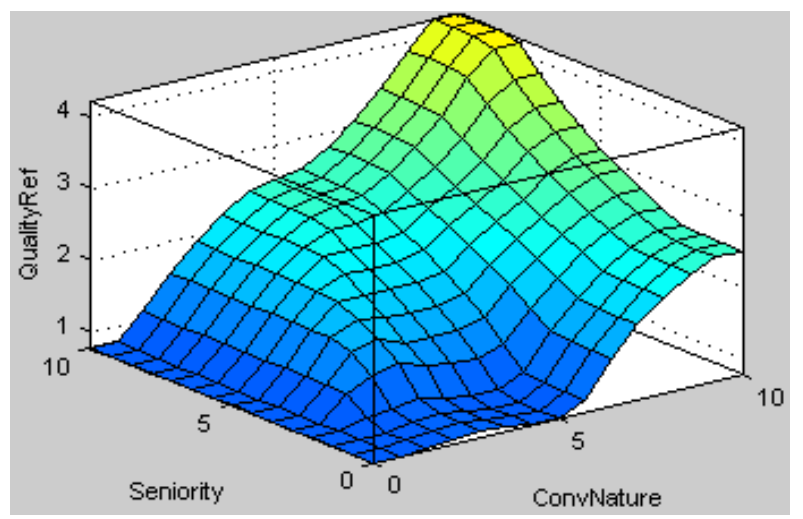

Fig 9. The surface of variation of QualityRef as function of ConvNature and Seniority

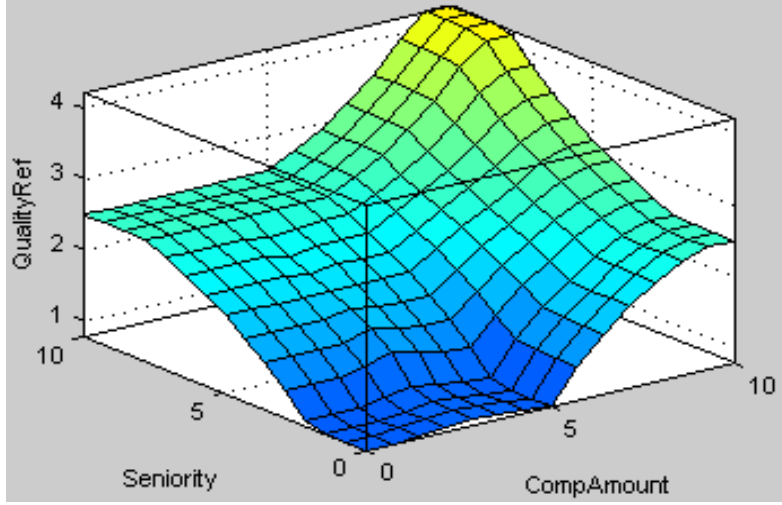

Fig 10. The surface of variation of QualityRef as function of CompAmount et Seniority

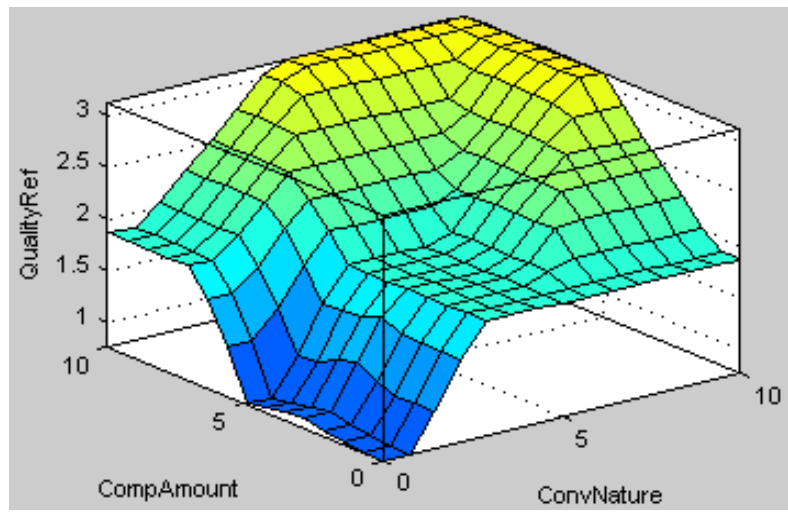

Fig 11. The surface of variation of QualiteRef as function of ConvNature and CompAmount

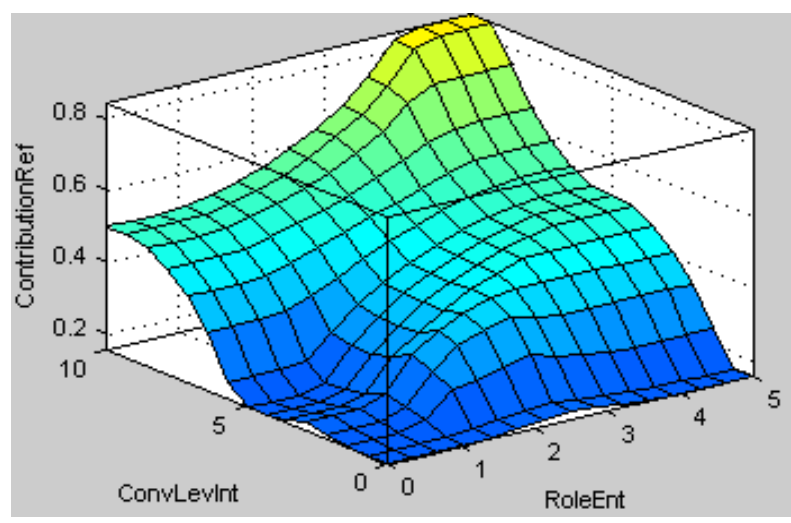

Fig 12. The surface of variation of ContributionEnt as function of RoleEnt et ConLevInt 


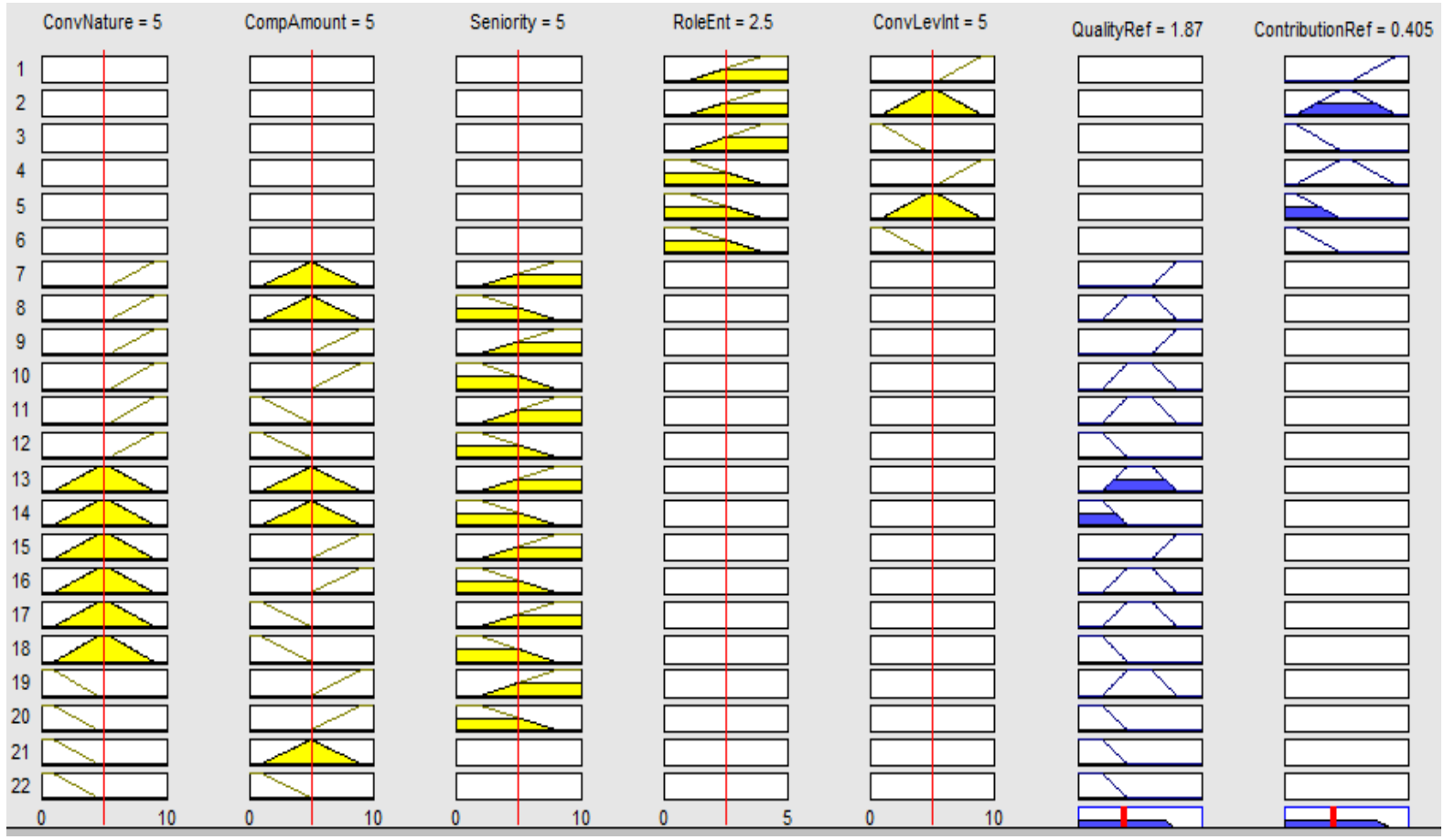

Fig 13: The variation of output variables QuallityRef and ContributionEnt

The figure 13 shows the "Rule viewer" which allows to vary the values of input variables and to obtain the values of output variables after variations. For each reference, it will used to obtain the values of "QualityRef" and "ContributionEnt" (some examples in table V).

\subsubsection{Exploitation of results}

\subsubsection{Principle of notation}

The results obtained using the software MATLAB will be used to give the note of each reference. To do this, the following method is used:

Let $E_{1}, E_{2}, E_{3}, E_{4}, \ldots, E_{l}, \ldots \ldots, E_{n}$ be, the $\mathrm{n}$ tenderers and

$$
\left\{\begin{array}{c}
\mathrm{R}_{\mathrm{lk}}: \text { The } \mathrm{k}^{\text {th }} \text { reference brought by the tenderer } \mathrm{E}_{\mathrm{l}} \\
\mathrm{Q}_{\mathrm{lk}}: \text { The result obtained by the } \mathrm{k}^{\text {th }} \text { reference of } \\
\text { tendererE } \mathrm{E}_{1} \text { at QualityRef } \\
\mathrm{C}_{\mathrm{lk}}: \text { The result obtained by the } \mathrm{k}^{\text {th }} \text { reference of the } \\
\text { tendererE } \mathrm{E}_{1} \text { at ContributionEnt } \\
\mathrm{N}\left(\mathrm{R}_{\mathrm{lk}}\right): \text { The note of tenderer } \mathrm{E}_{1} \text { for the acount of } \\
\text { the reference } \mathrm{R}_{\mathrm{lk}}
\end{array}\right.
$$

NB: In this case, each reference is rated out of 5 .

Considering the importance of the company contribution to the realization of the reference, $N\left(R_{l k}\right)$ is defined such that:

$$
N\left(R_{l k}\right)=C_{l k} * Q_{l k}
$$

Let $\mathrm{q}$ be the number of references brought by the tenderer $\mathrm{E}_{1}$ and $N_{R l}$ its note for the account of the award criterion "reference".

$$
N_{R l}=\sum_{k=1}^{q} N\left(R_{l k}\right)=\sum_{k=1}^{q} C_{l k} * Q_{l k}
$$

\subsubsection{Some examples of results}

In the table $\mathrm{V}$, some results given by Matlab:

\begin{tabular}{|c|c|c|c|}
\multicolumn{1}{c}{ TABLE V. } & Examples of Results \\
\hline & $\begin{array}{c}\text { Reference } \\
\text { A }\end{array}$ & $\begin{array}{c}\text { Reference } \\
\text { B }\end{array}$ & $\begin{array}{c}\text { Reference } \\
\text { C }\end{array}$ \\
\hline ConvNature & 5 & 7,9 & 9 \\
\hline CompAmount & 5 & 6 & 5 \\
\hline Seniority & 7 & 5,5 & 9 \\
\hline RoleEnt & 2,5 & 4 & 4,5 \\
\hline ConvLevInt & 5 & 2,5 & 9 \\
\hline QualityRef & 2.5 & 4,09 & 4,240 \\
\hline ContributionEnt & 0,627 & 0,344 & 0,847 \\
\hline $\begin{array}{c}\text { Note obtained } \\
\text { by the reference }\end{array}$ & 1,568 & 1,410 & 3,591 \\
\hline
\end{tabular}

If the three references were brought by the same tenderer $E_{l}$, its note according to the criterion "Reference" is:

$$
N_{R l}=\sum_{k=1}^{3} N\left(R_{l k}\right)=0,156+1,410+3,591=6,3
$$

\section{CONCLUSION AND PERSPECTIVES}

The analysis and evaluation stage is very important in the process of tendering. The methods proposed so far contain a plenty of shortcomings from where the need to improve or propose new methods.

This work includes two major improvements in the stage of analysis and evaluation of tenders whose use will bring more correctness in the choice of the best tender.

At first, a new method is proposed that simultaneously takes into account the intrinsic value and the relative value of each tender.

Secondly, fuzzy logic principles are introduced in the evaluation of criterion "Reference" to overcome the 
limitations of classical logic in order to improve the step of analysis and evaluation of tenders.

In the context of e-government (e-tendering), these improvements via methods of artificial intelligence and decision support will allow to implement IT solutions that will be able to resolve fully or partially the problems in the tendering process.

\section{REFERENCES}

[1] E. Auriol, "Corruption in procurement and public purchase", Int. J. Ind. Organ., vol. 24, n ${ }^{0}$ 5, September 2006, pp. 867-885.

[2] G.Concha, H.Astudillo, M.Porrúa and C.Pimenta, "Egovernment procurement observatory, maturity model and early measurements', Government Information Netwoeks, vol.29, Janvier 2012, pp.43-650.

[3] M.A.Hanine, "La procédure de passation des marchés publics au Maroc: étude analytique et réflexions à la lumière du code français des marchés publics (et des directives européennes) et des directives de la banque mondiale", Mémoire de master, Strasbourg.France : Ecole nationale d'administration, 2008.

[4] C. Nash and M. Wolański, "Workshop report Benchmarking the outcome of competitive tendering", Res. Transp. Econ., vol. 29, n ${ }^{\circ}$ 1, janv. 2010, pp. 6-10.

[5] T.C.Du, "Building an automatic e-tendering system on the Semantic Web", Decision Support Systems, vol.47, April 2009, pp. 13 -21

[6] Trésorerie générale du Maroc, "Le programme de dématérialisation des marchés publics", La revue AL KHAZINA de la trésorerie générale du Maroc, Rabat.Maroc, 2009.

[7] P.Chu,N.Hsiao,F.Lee and C.Chena, "Exploring success factors for Taiwan's government electronic tendering system: behavioral perspectives from end users", Government Information Quarterly, vol.21, February 200, pp.219-234.

[8] S.Bhagat, M.Dong, D.Hirshleifer and R.Noah, "Do tender offers create value? New methods and evidence", Journal of Financial Economics, vol.76, Decembre 2004, pp.3-60.

[9] J.D.Botero, C.Béler and D.Noyes, "Maitrise des risques dans le processus d'appel d'offres",,[QUALITA2013, Compiègne : France, 2013].

[10] D.J. Watt,B. Kayis and K. Willey, "Identifying key factors in the evaluation of tender for projects and services", International Journal of Project Management, vol.27, April 2009, pp.250-260.

[11] C.A.B.Costa, É.C.Corrêa, J.D.Corte and J.Vansnick, "Facililating bid evaluation in public call for tenders: A socio-technical approach', Omega, vol.30, June 2002, pp.227-242.

[12] D.J. Watt,B. Kayis and K. Willey, "The relative importance of tender evaluation and contractor selection criteria', International Journal of Project Management, vol.28, January 2010, pp.51-60.

[13] M.A.Bergman and S.Lundberg, " Tender evaluation and supplier selection methods in public procurement", Journal of Purchasing and Supply Managmeent, vol.19, June 2013, pp.73-83.

[14] M.V.Rillaed, "Critères d'attribution - Choix, pondération, cotation et motivation", Mouvement Communal, Belgique, 2011

[15] F.Lichère and F.Marty, "Remedies in the Field of Public Procurement Law in France and in the USA: a Legal and Economic Comparison.", Remedies and Economics, 2011

[16] C.Lin, H.ChiuandY.Tseng, “Agility evaluation using fuzzy logic," International Journal of Production Economics, vol.101, June 2006, pp.353-368.

[17] L.Osiro, F.R.Lima-Juniorand L.C.R.Carpinetti, " A fuzzy logic approach to supplier evaluation for development", International Journal of Production Economics, February 2014.

[18] G.Gokmen, T.Ç.Akinci, M.Tektaş, N.Onat, G. KocyigitandN.Tektaş, "Evaluation of student performance in laboratory applications using fuzzy logic', Procedia - Social and Behavioral Sciences, vol.2, 2010, pp.902-909.

[19] S.K.Issa, A.Azmani and B.Amami, "Vulnerability Analysis of Fire Spreading in a Building using Fuzzy Logic and its Integration in a Decision Support System', International Journal of Computer Applications, vol.76, August 2013

[20] M.Wulan and D.Petrovic, " A fuzzy logic based system for risk analysis and evaluation within entreprise collaborations," Computer in Industry, vol.63, July 2009, pp.739-748.

[21] S.E.Kadiri, M.Delattre, P.Pernelle and A.Bouras, "Une approche de construction des indicateurs de suivi basée sur la logique floue," [1 er Colloque International sur les Systèmes Industriels et Logistiques (SIL'08), Marrakech.Maroc, 2008]

[22] V.Novák, J.Močkoř and I.Perfilieva, "Mathematical principles of fuzzy logic", Boston.Mass : Kluwer Academic, 1999.

[23] K.H.Lee, "First course on Fuzzy Theory and Applications,"'Springer, October 2004

[24] V.Novák, J.Močkoř and I.Perfilieva, "Mathematical principles of fuzzy logic', Boston.Mass: Kluwer Academic, 1999

[25] L.A.Zadeh, "Toward a theory of fuzzy information granulation and its centrality in human reasoning and fuzzy logic', Fuzzy Sets and Systems, vol. 90, 1997, pp.111-127.

[26] B.Bouchon-Meunier and C.Marsala, "Logique floue, principes, aide à la décision", Hermès science, Paris : Lavoisier, 2003 